\title{
Consumption Invariant to Economic Downturn? Evidence on the Propensity to Consume
}

\author{
Y. Zarinah and G. P. P. Jenny Pereira
}

\begin{abstract}
This paper analyzes the response of consumption spending in Malaysia to the changes in income with consideration of the recent economic downturn of 1997/1998 and 2008. Applying annual data over the period 1991-2010, the cointegration test and the error correction model were employed to measure the response. Marginal propensity to consume in the short run and the long run were estimated. The finding finds that despite extraordinary times, consumption spending is invariant to economic downturn. It rejects excessively volatile consumption behavior and supports a stable consumption pattern. The marginal propensity to consume 0.67 is consistent with some findings in the literature. Wealth is one of the significant determinants of consumption.
\end{abstract}

Index Terms-Consumption, cointegration, error correction model, financial crisis

\section{INTRODUCTION}

In recent years consumption has been given much attention to stimulate growth. This is critical when exports and investment spending failed to take a lead as the engine of growth. Contributing about 50-70\% of GDP, it makes consumption as one of the main drivers to the sustainability of economic growth. Based on modern economic theory, consumption is closely linked to lifetime income. Availability of credit allows consumption to go higher than household's income. Therefore, increased financial deepening and innovation is an integral part in supporting consumption,which facilitating greater access to credit. Consumption is a forward-looking behavior. Household's spending is influenced by the long-term consideration such as retirement life and meeting emergencies payment. Hence, households adjust gradually to any changes in the level of income. The life-cycle and permanent income hypotheses explain that consumption responds more to permanent changes in income and reject excessive volatile pattern in consumption. However, a controversy has developed over the issue, as evidence on visible response of consumption to the decline in income have been found by Kaplan and Violate (2011), Parker, Souleles, Johnson and McClelland (2011) and Flavin (1981).

Undoubtedly, the Asian financial crisis 1997-1998 and the global financial crisis 2007-2008 have adversely affected many economies. Countries suffered continuous currency depreciation, stock markets crash, banking crisis, company's

Manuscript received October 5, 2012; revised November 15, 2012.

Y. Zarinah is with the Faculty of Economics and Administration, University of Malaya, 50603 Kuala Lumpur, Malaysia (e-mail: zarinahy@ um.edu.my)

G. P. P. Jenny Pereira is with the Faculty of Economics and Administration, University of Malaya, 50603 Kuala Lumpur, Malaysia (e-mail: jennypereira28@hotmail.com). bankruptcy and retrenchment of workers. Although almost all Asian economies were affected by the crises but the magnitude differs across the countries. It is the concern of this paper to study the effect of these crises on household consumption. Specifically, this paper examines the dynamic link of consumption-income relationship and finding whether consumption in Malaysia is adversely affected by the financial crises. Using the marginal propensity to consume, it analyzes whether consumption is responding strongly to changes in actual income or behaves in a smoother pattern. The study helps policymakers to understand better the behavior of household consumption in Malaysia. It offers the estimate of multiplier effect from the estimated marginal propensity to consume. This is crucial for an effective fiscal stimulus program and macroeconomic management. Moreover, up to the present time, research on consumption behavior in Malaysia is scanty and this serves as a strong motivational drive of this study.

The rest of this paper is organized as follows. Section II discusses literature review related to the issue of consumption. Section III presents the methodology of the study and the analysis of the findings is given in the Section IV. Finally, Section V concludes the study by highlighting the key findings of this study.

\section{LITERATURE REVIEW}

Keynes in his theory explains that consumption is strongly affected by current disposable income. People consume about $80-90 \%$ from disposable income. In contrast, the modern consumption theory of life-cycle hypothesis and permanent-income hypothesis argue that most people favor a stable consumption. In other words, consumption is less responsive to current income but react more to long-run income.This implies that consumption adjusts slowly over time and is a stable function.

However, some scholars argue that in the present of liquidity constraint or unavailability of credit, consumption is strongly affected by current income and fluctuates with changes in income. This is supported by Flavin (1981) as she finds that consumption is excessively volatile and it reacts strongly to changes in income. Similarly, in more recent studies, Kaplan and Violate (2011) and Parker, Souleles, Johnson and McClelland (2011), find that households respond significantly to changes in current income. Utilizing data from 2001, Kaplan and Violate (2011) explain that many wealthy households are hand-to-mouth. They hold little liquid wealth for consumption spending despite making huge illiquid assets and hence, display large propensities to consume from current income. Parker, Souleles, Johnson and McClelland (2011) exploiting data from Consumer 
Expenditure Survey analyse the response of American households to the fiscal stimulus payment tax rebates in 2008. They find that there was a large aggregate increase in consumption from a tax rebate stimulus payments in 2008. Households responded immediately only when the actual payment was made. Thus, attempt is made in this study to investigate how far consumption spending in Malaysia is responsive to changes in income and explained by the modern consumption theory of life-cycle hypothesis and permanent-income hypothesis.

Generally, many of the past studies on consumption behavior are exclusively focusing on the US economy (Holbrook and Stafford, 1971; Hall, 1978; Sargent, 1978; Balla 1979; Hall and Mishkin, 1982; Hayashi, 1982; Flavin, 1981 and 1985, Mankiw, 1981, Zeldes 1985 and, Campbell and Mankiw, 1990). Time series data are applied to the rational expectations permanent income hypothesis in the studies by Hall (1978), Sargent (1978), Flavin (1981 and 1985) and Mankiw (1981). Panel data are used in the studies of Holbrook and Stafford (1971), Bhalla (1979), Hayashi (1985), Zeldes (1985) and Altonji and Siow (1987).

To cite some studies in Malaysia, the recent work of Eu Chye (2009) and Ismail (2010) are considered here. In both studies, models are not tested sufficiently using the latest econometric method. Eu Chye (2009) investigates private consumption behavior by analyzing the average share of private consumption in the GDP. Ismail (2010) examines the relationship between government spending and private consumption in Malaysia and concludes that government spending raises consumption spending and complementary to each other. It rejects the government spending crowding out effect on consumption spending by households. Hence, in this study, we take a different approach by proving more evidence on the propensity to consume, in specific, marginal propensity to consume out of current income, marginal propensity to consume out of long-run income and marginal propensity to consume out of wealth. Also, the empirical work on consumption behavior takes more comprehensive estimation procedures via the cointegration test and ECM estimation utilizing more recent data. Diagnostic tests were performed to check for the robustness of the results.

\section{Methodology AND DATA}

The analysis uses cointegration test, vector autoregressive (VAR) and error correction model (ECM) estimation. The analysis spans from 1991 to 2010. Data sources are from International Monetary Fund (IMF) and Monthly Statistical Bulletin, Bank Negara Malaysia. Before estimating the model, it is important to examine the time series properties of the data. Many macroeconomics variables are not stationary in their level form (Harris, 1995 and Dickey et al., 1991). Often they seem to be trending upward in a stochastic fashion. This indicates that the variables have no tendency to revert to their mean value. As such, regression involving non-stationary time series is meaningless although the good-of-fit of the model is very high. However, if the non-stationary series are cointegrated the estimates are not dubious. Cointegration implies that there always exists a linear combination of these variables that is stationary. Provided that the variables have a common trend, if a number of variables are cointegrated, there is a corresponding error correction representation (Engle and Granger, 1987). In short, changes in the dependent variables depend on the level of disequilibrium in the cointegrating relationship and changes in the other explanatory variables. Cointegration is only possible when each of the series is integrated the same order. The Augmented Dickey-Fuller (ADF) and Phillips Perron (PP) tests are used to test the order of integration of the series.

The cointegration analysis adopted here follows Johansen and Juselius (JJ) (1992) method. It is a multivariate cointegration analysis using a maximum likelihood estimation procedure. The method is different from Johansen and Juselius (JJ) (1990) procedure that commonly being applied in the literature. In JJ (1992), VAR models are estimated with unrestricted intercepts and restricted trends. That is, the cointegrating system equations include a constant term and trend variable. This will ensure linear trends in the series. Generally, the cointegration analysis is based on the model as follows,

$$
y_{t}=A_{0}+A_{1} y_{t-1}+\cdots+A_{k} y_{t-k}+\Psi D_{t}+\varepsilon_{t}
$$

where $y_{t}$ is a $(p \times 1)$ vector of $I(1)$ variables, $A_{0}$ is a $(p \times 1)$ vector of constant, $A_{i}$ and $\Psi$ are the estimated parameters, $D_{t}$ comprises seasonal dummy variables, external shock and policy intervention such that $I(0)$ and $\varepsilon_{t}$ represents unanticipated movement in $y_{t} ; \varepsilon_{t} \sim N_{p}(0, \Omega)$. It is a reduced form system equations where all of the variables are assumed jointly endogenous.

Alternatively, a VAR representation in first order differences is,

$$
\begin{array}{r}
\Delta y_{t}=A_{0}+\Gamma_{1} \Delta y_{t-1}+\cdots+\Gamma_{k-1} \Delta y_{t-k+1}+ \\
\Pi y_{t-k}+\Psi D_{t}+\varepsilon_{t}
\end{array}
$$

$\Gamma_{i}=-\left(I-A_{1}-\cdots-A_{i}\right), \quad \Pi=-\left(I-A_{1}-\cdots-A_{k}\right) \quad(i=1, \ldots, k-1 ; \quad t=1, \ldots, T)$,

is the first differenced, $L$ is the lag operator. The rank of matrix $\Pi$ determines the linear combinations of $y_{t}$ that are stationary. The rank of matrix $\Pi, \mathrm{r}$, is the number of cointegrating vectors. For $1<\operatorname{rank}(\Pi)=r<p$, there are multiple cointegrating vectors. The JJ procedure measures the number of rank in matrix $\Pi$. The JJ procedure is based on trace test and maximal eigenvalues test. The trace test is computed as $\lambda_{\text {trace }}(r)=-T \sum_{i=r+1}^{p} \ln \left(1-\hat{\lambda}_{i}\right)$ and themaximal eigenvalue test is calculated as $\lambda_{\max }(r, r+1)=\mathrm{T} \operatorname{In}(1-$ $\left.\hat{\lambda}_{r+1}\right)$.

After identifying the cointegration relationship we proceed to estimating the channels using VECM. This will give more insight into the relationship between the channels and economic activity, particularly on the relative strength of the channels. The cointegrating vectors obtained earlier cannot be interpreted as structural equations simply because they are 
reduced form equations. The VECM with lag-length $p$ and incorporating an error correction term, $\beta^{\prime} y_{t-1}$ is expressed as

$$
\begin{gathered}
\Delta y_{t}=A_{o}+\sum_{i=1}^{p-1} \Gamma_{i} \Delta y_{t-i}+\alpha \beta^{\prime} y_{t-p}+u_{t} \\
\alpha \beta^{\prime}=\Pi=-\left[I-\sum_{i=1}^{k} A_{i}\right] \text { and } \Gamma_{i}=-\left[I-\sum_{i=1}^{i} A_{j}\right]
\end{gathered}
$$

where $\Gamma=\alpha \beta^{\prime}$, matrices $\alpha$ and $\beta$ are (n x r) dimension, $r$ is the rank of matrix $\Gamma$ as before. The matrix $\beta$ is the long-run coefficients (cointegrating parameters) and the matrix $\alpha$ represents speed of adjustments to disequilibrium. The Granger-causality is explained through i) the short-run causality relationship in the differenced variables, $\Delta y_{t-i}$ and ii) the long-run dynamic causal link in the long-run co-movements (error correction term) of the variables, $y_{t-p}$ (Masih and Masih, 1996). The estimating model is given as

$$
\begin{aligned}
\Delta \text { Con }_{t}= & B_{0}+\sum_{i=1}^{k} \beta_{1} \Delta \text { LCon }_{t-i}+\sum_{i=1}^{k} B_{2} \Delta L Y d_{t-i} \\
& +\sum_{i=1}^{k} B_{3} \Delta L W_{t-i}+\phi C R I S 9808 \\
& +\gamma E C T_{t-1}+\varepsilon_{t}
\end{aligned}
$$

where $B_{0}>0,0<B_{1}, B_{2}, B_{3}<1, \mathrm{u}_{\mathrm{t}}$ is $\mathrm{E}\left(\mathrm{u}_{\mathrm{t}}\right)=0, \mathrm{LCon}_{\mathrm{t}}$ is consumption, $\mathrm{LYd}_{\mathrm{t}}$ is disposable income (GDP minus income tax), $\mathrm{LW}_{\mathrm{t}}$ is wealth, CRIS9808 is a dummy variable measuring the financial crises in 1998 and 2008, $E C T$ is error correction term, $\mathrm{u}_{\mathrm{t}}$ is white- noise error term. $\mathrm{L}$ denotes logarithms. LCon and LYd are in real terms. Stock returns are used as a proxy for wealth.

\section{FINDINGS}

The results for unit root test using Augmented Dickey Fuller (ADF) and Phillips Perrontests suggest that all variables are integrated of order $1, \mathrm{I}(1)$ (Table I). The ADF and PP statistics are not sufficiently large to reject the null hypothesis of unit root in the level series with trend or without trend. This suggests that the level data contain unit root. The presence of unit root is rejected for all the variables when first-differenced data are used. The ADF and PP statistics, $\tau_{\mu}$ on almost all the series are very statistically significant at 5 per cent level.

Next cointegration test is performed on the $\mathrm{LCon}_{t}, \mathrm{LYd}_{\mathrm{t}}$ and $\mathrm{LW}_{\mathrm{t}}$ to determine the existence of any long-run relationship between the series. The maximum order of lags is $k=1$. The finding shows that all the series are cointegrated

\begin{tabular}{|c|c|c|c|c|c|c|}
\hline \multicolumn{7}{|c|}{ Augmented Dickey-Fuller (ADF) } \\
\hline & \multicolumn{6}{|c|}{ Ho:Unit Root } \\
\hline \multirow[t]{2}{*}{ Series } & \multicolumn{4}{|c|}{ Level } & \multicolumn{2}{|c|}{ Difference } \\
\hline & $k$ & $\tau_{\mu}$ & $k$ & $\tau_{\tau}$ & $k$ & $\tau_{\mu}$ \\
\hline LCon & 2 & -0.0503 & 2 & -2.8284 & 1 & $-3.7191^{b}$ \\
\hline LYd & 1 & -2.2999 & 1 & -1.6602 & 1 & $-3.0687^{b}$ \\
\hline LW & 1 & -1.8730 & 1 & -2.1726 & 1 & $-4.6174^{\mathrm{a}}$ \\
\hline $\mathrm{r}$ & 1 & -0.0897 & 7 & -2.0780 & 2 & $-3.4262^{\mathrm{b}}$ \\
\hline \multicolumn{7}{|c|}{ Phillips-Perron (PP) } \\
\hline & \multicolumn{6}{|c|}{ Ho: Unit Root } \\
\hline \multirow[t]{2}{*}{ Series } & \multicolumn{4}{|c|}{ Level } & \multicolumn{2}{|c|}{ Difference } \\
\hline & $k$ & $\eta_{\mu}$ & $k$ & & $k$ & $\eta_{\mu}$ \\
\hline LCon & 3 & -0.2419 & 3 & -2.9290 & 3 & $-5.2508^{\mathrm{a}}$ \\
\hline LYd & 2 & -2.4386 & 2 & -1.0898 & 1 & $-3.6262^{\mathrm{a}}$ \\
\hline LW & 2 & -2.1083 & 2 & -2.4423 & 4 & $-4.9858^{\mathrm{a}}$ \\
\hline r & 1 & -0.6995 & 6 & -2.4777 & 6 & $-4.2395^{\mathrm{a}}$ \\
\hline
\end{tabular}
(Table II). Both $\lambda$-max and trace statistics tests reject the null hypothesis of no cointegration $(r=0)$ at the 5 per cent significant level in most of the cases. There is at least one cointegrating vector at 5 per cent significant level.
Notes: $a$, and $b$ represents significant level at 1 per cent and 5 per cent respectively. The Augmented Dickey Fuller test statistics are computed with an intercept, a linear time trend and $k$ lagged first-differences of the series to the series in level. The ADF regression in first-differences, exclude a linear time trend. The lag length ( $\mathrm{k}$ ) was selected based on Akaike Information Criteria (AIC). At $\mathrm{n}=25$, the ADF critical values are -3.75 ( 1 per cent), -3.00 ( 5 per cent] and $-2.62\left(10\right.$ per cent) for constant $\left(\tau_{\mu}\right) ;-4.38$ ( 1 per cent), -3.60 ( 5 per cent) and -3.24 (10 per cent) for constant and time trend $\left(\tau_{\tau}\right)$.

TABLE II: COINTEGRATION TEST

\begin{tabular}{lccccc}
\hline \multicolumn{6}{c}{ TABLE II: COINTEGRATION TEST } \\
\hline \multicolumn{7}{c}{ Hypotheses } & \multicolumn{5}{c}{ Test Statistics } \\
\hline $\mathrm{H}_{0}$ & $\mathrm{H}_{1}$ & Max Eigen & $\lambda_{\max }$ & Trace & $\lambda_{\text {trace }}$ \\
\hline \multicolumn{7}{l}{ Vector:[LCon, LYd, LW] k=1 } \\
r=0 & $\mathrm{r}>0$ & $25.51^{*}$ & 21.13 & $33.03^{*}$ & 29.80 \\
$\mathrm{r} \leq 1$ & $\mathrm{r}>1$ & 4.98 & 14.26 & 7.52 & 15.49 \\
$\mathrm{r}=2$ & $\mathrm{r}>2$ & 2.53 & 3.84 & 2.53 & 3.84 \\
& \\
$*$
\end{tabular}

Subsequently, the model is regressed by applying the error correction modeling technique. Interestingly, finding from the cointegrating vector or the long-run relation shows that consumption is strongly affected by long-run income with marginal propensity to consume (mpc) of 0.67 . A rise in disposal income by one per cent raises consumption by 0.67 per cent. The estimate is consistent with the recent empirical work on the impact of fiscal stimulus of $\$ 100$ billion payments to 130 million households in the United States where the mpc is 0.68 (Parker, 2011). Consumption is also significantly influenced by household wealth and the mpc is as expected, relatively low value of 0.22 . An increase in one per cent in wealth increases consumption spending by 0.22 per cent. This finding supports the modern theory of consumption and rejects the simple Keynes theory of consumption.

\section{Cointegrating Vector:}

$\operatorname{LCon}_{\mathrm{t}-1}=2.611871+0.675617 \mathrm{LYd}_{\mathrm{t}-1}+0.219540 \mathrm{LW}_{\mathrm{t}-1}$ (36.7312)

More finding is evidence from the estimate of error correction model. All the variables of interest have the expected signs and statistically significant. Consumption 
reacts little to changes in income in the short run and even more, the coefficient is statistically insignificant different from zero. Changes in wealth have some positive effects on household consumption and as usual the response is small. An increase in one per cent in wealth drives up consumption only by 0.13 per cent and the coefficient is smaller than the long run. The result suggests that households are less likely to use their wealth to finance spending. They rely more on income than wealth. Households hold wealth in real property, bank deposit and financial portfolio, which give returns over time. Liquidating these assets means they have to forgo the returns. As wealth affects consumption spending, maintaining financial stability is important for sustainable economic growth. Moreover, higher wealth provides more capital to the economy and promotes higher economic growth.

The result also suggests that the country is affected by the economic downturn in 1998 and 2008 as consumption is affected negatively. Nevertheless, the effect on consumption is small (.08) as people believe that this is only temporary shock to the economy. Hence, this study finds consumption is invariant to economic downturn. The evidence from long-run relationship shows that any disequilibrium in the system will be closed by consumption converging moderately at a speed of adjustment $34 \%$. In other words, in the short run, deviations from long-run equilibrium would initiate response from consumption to move back the economy to its equilibrium. The robustness of the findings is supported by the diagnostic tests. The residuals are all well behaved. The $\mathrm{R}^{2}$ of the regression is high, that is 83 per cent of variation in consumption spending is well explained by households disposable income, wealth variable and dummy crisis variable. The estimates are also free the problems of serial correlation, normality and heteroscedasticity.

\section{Error Correction Model:}

$\Delta \mathrm{LCon}_{\mathrm{t}}=0.0687-0.2194 \Delta \mathrm{LCon}_{\mathrm{t}-1}+0.0979 \Delta \mathrm{LYd}_{\mathrm{t}-1}$

$$
(-1.48020)
$$

$+0.1289 \Delta \mathrm{LW}_{\mathrm{t}-1}-0.0849$ Crisis9808 $-0.3387 \mathrm{ECT}_{\mathrm{t}-1}$

( 4.43219)(-3.42491) (2.28278)

\author{
Diagnostic Tests: \\ R-squared $=0.830835$ \\ Adj. R-squared $=0.760350$ \\ Jarque-Bera $=1.177804(0.554936)$ \\ Breusch-Godfrey LM Test $\mathrm{F}(4,8)=0.568768(0.6929)$ \\ Heteroskedasticity ARCH Test $\mathrm{F}(1.15)=0.003661(0.952)$
}

\section{CONCLUSION}

This paper examines the behavior of household consumption in Malaysia using data from 1991-2010. In particular, it analyzes whether consumption spending in Malaysia is excessively sensitive to changes in current disposable income and the economic downturn of 1998 and 2008. The findings reveal that consumption spending in Malaysia remains relatively stable over the past years despite the turbulent years. Households are more responsive to income in the long run and less to current income. In general, people tend to smooth out any change in income. Wealth is one of the factors that affect consumption but the effect is relatively low.
This finding suggests that any fiscal policy stimulus that targeted income is appropriate and relevant. However, such cash payments or income tax refunds to the people must be made large for it to have significant effect on the economy. Since there is a tendency that people may not be spending all the income received and also most likely the payments are not spent on goods and services instead for paying debt or saved. Therefore, money payment using voucher that link to specific purchases is another way to do. The recent money payment to the lower-income group is a right move to increase domestic spending. This is because lower-income group's mpc is higher than high-income group. The government should also consider extending the money to the middle-income group based on their ability to consume.

\section{REFERENCES}

[1] D. Dickey, D. Jansen, and D. Thorton. 1991. A primer on cointegration with an application to money and income. Federal Reserve Bank of St Louis Review. vol. 73. pp. 58-78. [Online]. Available: http://research.stlouisfed.org/publications/review/91/03/.

[2] F. Hayashi, "The permanent income hypothesis and consumption durability: analysis based on Japanese panel data," The Quarterly Journal of Economics, 1985, no. 1083-13.

[3] G. Kaplan and G. Violante, "A Model of the Consumption Response to Fiscal Stimulus Payments," National Bureau of Economic Research Working Paper, 2011, no. 17338.

[4] J. G Altonji and A. Siow, "Testing the response of consumption to income changes with (noisy) panel data," The Quarterly Journal of Economics, 1987, vol. 102, no. 2, pp. 293-328.

[5] J. Y. Campbell and N. G. Mankiw, "Permanent income, current income and consumption," Journal of Business \& Economic Statistics, vol. 8, no. 3, 1990, pp. 265-279.

[6] M. A. Flavin, "The adjustment of consumption to changing expectations about future income," Journal of Political Economy, 1981, vol. 86, pp. 974-1009.

[7] M. A. Flavin, "Excess sensitivity of consumption to current income: liquidity constraints or myopia?" Canadian Journal of Economics, 1985, vol. 18, pp. 117-36.

[8] N. A. Ismail, "Does government spending crow out private consumption in Malaysia," Jurnal Kemanusian, 2010, vol. 16.

[9] N. G. Mankiw, "The permanent income hypothesis and the real interest rate," Economics Letters, 1981, vol. 7, pp. 307-11.

[10] J. A. Parker, N. C. Souleles, D. S. Johnson, and R. McClelland, Consumer spending and the Economic Stimulus Payment of 2008, 2011, NBER Working Papers 16684, National Bureau of Economic Research, Inc.

[11] R. E. Hall, "Stochastic implications of the life cycle-permanent income hypothesis: theory and evidence," Journal of Political Economy, 1978, vol. 86, pp. 971-87.

[12] R. F. Engle and C. W. J. Granger, "Cointegration and error correction: Representation, estimation and testing," Econometrica, vol. 55, 1987, pp. 251-276.

[13] R. Holbrook and F. Stafford, "The propensity to consume separate types of income: a generalized permanent income hypothesis," Econometrica, 1971, vol. 39, pp. 1-22.

[14] R. I. D. Harris, 1995, Using Cointegration Analysis in Econometric Modelling, Hemel Hempstead: Prentice Hall.

[15] R. J. Gordon, "Macroeconomics," Pearson, 2012.

[16] R. Masihand and A. M. M. Masih, "Macroeconomic activity dynamics and granger causality: New evidence from small developing economy based on a vector error correction modeling analysis," Economic Modelling, vol. 13, 1996, pp. 407-426.

[17] R. E Hall and F. S. Mishkin, "The sensitivity of consumption to transitory income: estimates from panel data on households," Econometrica, 1982, March, pp. 261-81.

[18] S. S. Bhalla, "Measurement errors and the permanent income hypothesis: evidence from rural India," American Economic Review, 1979, vol. 69, pp. 195-207.

[19] S. Zeldes, Consumption and liquidity constraints: an empirical investigation, Working Paper, no. 24-85, 1985. Wharton School, University of Pennsylvania.

[20] T. E. Chye. "Private consumer expenditure in Malaysia: theories and evidence." International Journal of Applied Business and Economic Research. 2009, vol. 7, no. 2, pp. 107-120.

[21] T. J. Sargent, "Rational expectations, econometric exogeneity and consumption," vol. 86, 1978, pp. 673-700. 